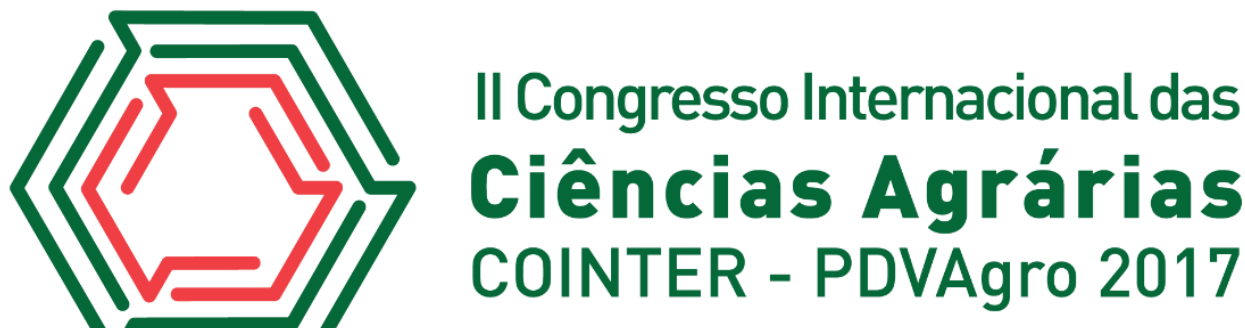

\section{COMPOSIÇÃO QUÍMICA DA SILAGEM DE SORGO COM ADIÇÃO DE BAGAÇO DE CAJU DESIDRATADO: MATÉRIA SECA, PROTEÍNA BRUTA, FDN E FDA}

Apresentação: Comunicação oral

\author{
Jesane Alves de Lucena ${ }^{1}$; Vítor Lucas de Lima Melo² ${ }^{2}$ Raisa Raquel da Cunha Menezes ${ }^{3}$; Cicília \\ Maria Silva de Souza ${ }^{4}$; Hilton Felipe Marinho Barreto ${ }^{5}$
}

\begin{abstract}
Resumo
O objetivo desse trabalho foi determinar a composição química da silagem de sorgo associado ao bagaço de caju em diferentes níveis de substituição. $\mathrm{O}$ ensaio experimental foi conduzido no Instituto Federal de Educação, Ciência e Tecnologia do Rio Grande do Norte (IFRN) - Campus Apodi. A silagem foi confeccionada com a forragem de sorgo (Sorghum bicolor) e por bagaço de caju substituindo-se no momento da ensilagem pelo bagaço do caju desidratado (BCD) nas proporções de $0 ; 8 ; 16$ e 24\%, com base na matéria natural. Foram confeccionados 96 minissilos, sendo preenchidos com as matérias-primas, previamente trituradas e homogeneizadas, e compactadas, abertos aos 3, 7, 14, 21, 28 e 35 dias de armazenamento. Foram coletadas alíquotas de $300 \mathrm{~g}$ da silagem no momento da ensilagem e na abertura dos minissilos, sendo posteriormente determinados os teores de matéria seca (MS), proteína bruta (PB), fibra insolúvel em detergente neutro (FDN) e fibra insolúvel em detergente ácido (FDA) de acordo com a metodologia descrita por Detmann et al. (2012). As crescentes substituições do bagaço de caju desidratado (BCD) proporcionaram elevações $(\mathrm{P}<0,05)$ nos teores de MS das silagens, sendo verificadas diferenças para esta variável em todos os níveis de substituição, independente do dia de armazenamento nos silos. Os teores de proteína bruta $(\mathrm{PB})$ das silagens foram elevados $(\mathrm{P}<0,05)$ com a substituição do BCD. A substituição da forragem de sorgo por 8 e $16 \%$ de BCD na ensilagem não promoveu diferenças $(\mathrm{P}>0,05)$ nos teores de FDN das silagens quando estes foram comparados aos teores obtidos nas silagens sem substituição da forragem de sorgo na maioria dos tempos de armazenamento. As variações observadas nos teores de FDN dentro de cada nível de substituição pelo $\mathrm{BCD}$, em relação aos diferentes dias de abertura dos silos, pouco contribuíram para que se pudesse concluir sobre os efeitos dos diferentes dias da ocorrência do processo fermentativo sobre os teores de FDN das silagens. A substituição da forragem de sorgo pelo bagaço de caju desidratado no momento da ensilagem pode ser realizada em até $16 \%$ por não comprometeu composição química da silagem.
\end{abstract}

Palavras-Chave: Bagaço de caju, Fibra em detergente neutro, Fibra em detergente ácido, Matéria seca, Proteína bruta

\footnotetext{
${ }^{1}$ Professora titular do centro de ciências agrárias, UFERSA, jesane@ufersa.edu.br

${ }^{2}$ Zootecnista, vitor_IIm@hotmail.com

${ }^{3}$ Zootecnista, raquelmeneses90@gmail.com

${ }^{4}$ Zootecnista e Docente do IFRN - Campus Apodi, cicilia.silva@ifrn.edu.br

${ }^{5}$ Zootecnista e Docente do IFRN - Campus Apodi, felipe.barreto@ifrn.edu.br
} 


\section{Introdução}

O Brasil se destaca na atividade frutífera sendo o terceiro maior produtor de frutas, atrás apenas da China e da Índia (RODRIGUES, 2015). A região Nordeste possui os maiores índices de produtividade das espécies frutíferas tropicais destacando-se principalmente o caju $(96,5 \%)$, melão (94,6\%), manga $(70,1 \%)$, coco $(68,9 \%)$, mamão $(52,4 \%)$, maracujá $(50,9 \%)$, goiaba $(45,4 \%)$, abacaxi $(43,5 \%)$, banana $(37,4 \%)$ e a melancia $(27,8 \%)$ (IBGE, 2016). Os Estados do Ceará, Rio Grande do Norte e Piauí com 356; 147 e 116 mil hectares plantados, respectivamente, apresentaram produção do pedúnculo de caju entre 2,0 milhões e 2,5milhões de toneladas por ano (LEITE et al., 2013). Durante os meses de alta produção ocorre um grande desperdício de pedúnculos no campo e principalmente nas indústrias, gerando um acúmulo de resíduo no meio ambiente e que, sem que haja um destino adequado, gera poluentes na atmosfera, água e solo (SIQUEIRA; BRITO, 2013).

Tendo em vista esses prejuízos, o aproveitamento desses resíduos da indústria de frutas tem o grande potencial de substituir, de forma parcial, alguns componentes básicos da composição das rações dos animais (RAMOS et al., 2006). Estudos relatam que os resíduos de frutas estudados apresentaram composições químicas semelhantes aos alimentos tradicionais como o farelo de algodão, milho e soja, atendendo as condições mínimas de funcionamento ruminal e evidenciando a capacidade desses subprodutos servirem como aliados a dieta dos animais.

Diante do exposto, o objetivo desse trabalho foi determinar a composição química da silagem de sorgo associado ao bagaço de caju em diferentes níveis de substituição.

\section{Fundamentação Teórica}

As regiões tropicais possuem inúmeras espécies forrageiras com grande potencial para alimentação animal, contudo, o sorgo vem sendo bastante utilizado por se tratar de uma espécie com alta capacidade produtiva e valor nutricional elevado (OLIVEIRA et al., 2010). O Sorgo (Sorghum bicolor, L. Moench) é uma das espécies forrageiras mais utilizadas por possuir alta capacidade produtiva, apresentar valores adequados de matéria seca (MS), por ser resistente às épocas de estiagem (ROSA, 2012), assim como por apresentar altas concentrações de carboidratos solúveis que são essenciais para que ocorra um processo fermentativo eficiente (NEUMANN et al, 2002).

Aliada às características adequadas para utilização do sorgo está o potencial de utilização de resíduos oriundos da indústria de beneficiamento de frutas, uma vez que o Brasil é um dos principais produtores de frutas do mundo, são mais de 42,5 milhões de toneladas produzidos em 2,2 
milhões de hectares distribuídos em toda sua extensão territorial (ALMEIDA et al., 2013). Na região Nordeste esse setor encontra-se em desenvolvimento mesmo com clima semiárido e os Estados do Rio Grande do Norte e Ceará lideram a produção frutícola. O uso de subprodutos agroindústrias, como no caso, o bagaço das frutas pode levar ao barateamento dos custos de produção desses animais e menor tempo de produção, já que a alimentação perfaz até $70 \%$ dos custos desta atividade (ALMEIDA et al., 2014).

Dentre as principais frutas cultivadas no Nordeste, o caju se destaca por produzir mais de $90 \%$ de toda produção nacional (IBGE, 2016), tendo como os principais produtores Ceará (48,4\%), Rio Grande do Norte $(23,5 \%)$ e Piauí (19,8\%). A produção anual do pedúnculo situa-se entre 2 e 2,5 milhões de toneladas, sendo desperdiçadas em média cerca de 1,5 milhão de toneladas, o que representa 75\% da produção dos noves Estados nordestinos (HOLANDA et al., 2010).

O caju em sua maioria é utilizado pela agroindústria para produção de sucos e doces, gerando um resíduo chamado bagaço de caju que pode ser reaproveitado na suplementação animal de forma natural ou desidratado. Segundo Moraes (2007) existem variações na composição química do bagaço de caju quanto aos teores de matéria seca, proteína bruta, fibra em detergente neutro e fibra em detergente ácido com valores variando de 86 a 91,52\%; 14 a 19,7\%; 55,9 a 79,2\% e 28,4 a $68,6 \%$, respectivamente, sendo necessária a avaliação da composição quando for associado a silagem de sorgo.

Dantas Filho et al., (2007) avaliando a viabilidade econômica da inclusão de polpa de caju desidratada $(0,10,20,30$ e 40\% de polpa de caju desidratada - PCD) na alimentação de ovinos, concluiu que dieta em níveis de até $30 \%$ proporcionou o melhor retorno econômico quando comparado com os outros níveis. Ferreira (2004) estudando características químicas e fermentativas das silagens de capim elefante (Pennisetum purpureum Schum) com diferentes níveis de adição de bagaço de caju, com níveis $0 \%, 12 \% \%, 24 \%, 36 \%$ e 48\%, conclui com base nos resultados obtidos, que a adição de bagaço de caju na ensilagem do capim elefante, melhorou suas características fermentativas e o valor nutricional, consumo das silagens, podendo então, ser utilizado na alimentação de ruminantes.

\section{Metodologia}

O ensaio experimental foi conduzido no Instituto Federal de Educação, Ciência e Tecnologia do Rio Grande do Norte (IFRN), no Módulo Experimental de Pequenos Ruminantes, pertencente ao Núcleo de Estudos em Avaliação de Plantas Forrageiro e Nutrição de Ruminantes no Semiárido do 
Instituto Federal de Educação, Ciência e Tecnologia do Rio Grande do Norte NUPPA/NUTRISA/IFRN, localizado no Município de Apodi/RN.

A silagem foi confeccionada com a forragem de sorgo (Sorghum bicolor), colhida quando os grãos atingiram o estágio farináceo, e por bagaço de caju, adquirido ainda úmido em agroindústrias de suco, desidratado em secador solar e, em seguida, triturado. No momento da ensilagem, o sorgo foi substituído pelo bagaço do caju desidratado (BCD) nas proporções de $0 ; 8 ; 16$ e 24\%, com base na matéria natural.

Foram confeccionados 96 minissilos com tubos PVC (50 cm de altura e $15 \mathrm{~cm}$ de diâmetro), sendo preenchidos com as matérias-primas, previamente trituradas e homogeneizadas, e compactadas com o auxílio de um soquete de madeira, procurando manter uma densidade próxima a $600 \mathrm{~kg} / \mathrm{m}^{3}$ e abertos aos 3, 7, 14, 21, 28 e 35 dias de armazenamento.

Foram coletadas alíquotas de $300 \mathrm{~g}$ da silagem no momento da ensilagem (pré-ensilagem) e na abertura dos minissilos, sendo as mesmas acondicionadas em sacos plásticos vedados, identificadas e armazenados em freezer. As análises foram realizadas no Laboratório de Nutrição Animal do IFRN - Campus Apodi, onde foram determinados os teores de matéria seca (MS), proteína bruta $(\mathrm{PB})$, fibra insolúvel em detergente neutro (FDN) e fibra insolúvel em detergente ácido (FDA) de acordo com a metodologia descrita por Detmann et al. (2012).

$\mathrm{O}$ delineamento experimental foi o inteiramente casualizado em esquema fatorial $4 \times 7$, sendo utilizados sete tempos de aberturas e quatro repetições. Após as análises foi realizada a análise de variância e o teste de Tukey, a 5\% de significância, para comparação de médias.

\section{Resultados e Discussões}

As crescentes substituições do bagaço de caju desidratado (BCD) proporcionaram elevações $(\mathrm{P}<0,05)$ nos teores de MS das silagens, sendo verificadas diferenças para esta variável em todos os níveis de substituição, independente do dia de armazenamento nos silos (Tabela 1). Os teores de MS variaram de $32,2 \%$ (nível $0 \%$ no $21^{\circ}$ dia de armazenamento) a 49,5\% (nível $24 \%$ no $35^{\circ}$ dia de armazenamento).

Em relação aos dias de armazenamento dos silos, no nível 0\% de BCD apenas o material pré-ensilado (tempo de abertura 0) diferiu $(\mathrm{P}<0,05)$ de todos os demais $(37,06 \%$ de $\mathrm{MS})$. Nos dias 3; 7 e 14, os teores de MS não diferiram entre si, com média de 35,53\%, enquanto que nos dois maiores tempos de armazenamento (28 e 35 dias) foram alcançados valores semelhantes $(\mathrm{P}>0,05)$, com média de $36,37 \%$ de MS. 
Tabela 1 - Teores médios de matéria seca (MS) de silagens de sorgo (Sorghum bicolor, L.) associada a níveis crescentes do bagaço de caju (Anacardium occidentale,L.) desidratado em diferentes tempos de armazenamento

\begin{tabular}{|c|c|c|c|c|c|}
\hline \multirow{2}{*}{$\begin{array}{c}\text { Dias de } \\
\text { armazenamento }\end{array}$} & \multicolumn{4}{|c|}{ Níveis de substituição do bagaço do caju desidratado (\%) } & \multirow{2}{*}{$\mathrm{CV}(\%)$} \\
\hline & 0 & 8 & 16 & 24 & \\
\hline 0 & 37,06 Ad & 38,44 Dc & $42,42 \mathbf{F b}$ & $44,37 \mathbf{E a}$ & \\
\hline 3 & 35,45 DEd & $39,38 \mathbf{~ C c}$ & $42,83 \mathbf{E F b}$ & $45,67 \mathbf{D a}$ & \\
\hline 7 & 35,32 DEd & $40,10 \mathbf{B c}$ & 43,64 CDb & $48,56 \mathbf{B a}$ & \\
\hline 14 & 35,83 CDd & $38,27 \mathbf{D c}$ & $43,91 \mathbf{C b}$ & $47,00 \mathbf{C a}$ & 0,32 \\
\hline 21 & $32,23 \mathbf{E d}$ & $40,34 \mathbf{B c}$ & $45,17 \mathbf{B b}$ & $48,47 \mathbf{B a}$ & \\
\hline 28 & $36,50 \mathbf{B d}$ & $40,07 \mathbf{B c}$ & 43,15 DEb & $46,80 \mathbf{C a}$ & \\
\hline 35 & $36,24 \mathbf{B C d}$ & 41,61 Ac & $46,03 \mathbf{A b}$ & $49,53 \mathbf{A a}$ & \\
\hline
\end{tabular}

Médias seguidas pela mesma letra maiúscula na mesma coluna e pela mesma letra minúscula na mesma linha não diferem pelo Teste de Tukey $(\mathrm{P}>0,05)$.

Diferentemente do observado para as silagens sem substituição do BCD, em todos os outros níveis (8; 16 e 24\%) em que o BCD substituiu o sorgo no momento da ensilagem, os maiores teores de MS foram obtidos apenas no $35^{\circ}$ dia de abertura dos silos $(41,61 ; 46,03$ e 49,53\%, respectivamente).

No nível de substituição de $8 \%$ do BCD, os teores de MS superaram os $40 \%$ de MS ( $\mathrm{P}>0,05)$ quando os silos foram abertos depois dos 7; 21; 28 e 35 dias de armazenamento. Enquanto que nos maiores níveis de substituição do BCD (16 e 24\%) os teores MS obtidos no material préensilado (tempo 0 de abertura do silo) já foram superiores a $40 \%$ (42,42 e 44,47\%, respectivamente) diferindo-os $(\mathrm{P}<0,05)$ daqueles obtidos nas silagens advindas dos silos abertos no $7^{\circ}$ a $35^{\circ}$ dias para o nível de adição de $16 \%$ de BCD e daqueles obtidos nas silagens oriundas dos silos abertos no $3^{\circ}$ a $35^{\circ}$ dias de armazenamento.

Nesse estudo verificou-se que não houve excesso de umidade no momento da ensilagem do sorgo já que, de acordo com a Tabela 1, o mesmo apresentou valores na pré-ensilagem de que variaram de 32,23 a 37,06\% de MS. Valores estes que se encontra dentro da faixa citada por Silveira (1975) como ideal para a ocorrência de uma boa conservação da forragem. No caso em questão, a adição do BCD fez com que os teores de MS fossem elevados alcançando-se o máximo 
de $49,53 \%$ de MS nas silagens com $24 \%$ de BCD oriundas dos silos que foram abertos no $35^{\circ}$ após a ensilagem.

Tabela 2 - Teores médios de proteína bruta (PB) de silagens de sorgo (Sorghum bicolor, L.) associada a níveis crescentes do bagaço de caju (Anacardium occidentale,L.) desidratado em diferentes tempos de armazenamento

\begin{tabular}{|c|c|c|c|c|c|}
\hline \multirow{2}{*}{$\begin{array}{c}\text { Dias de } \\
\text { Armazenamento }\end{array}$} & \multicolumn{4}{|c|}{ Níveis de substituição do bagaço do caju desidratado (\%) } & \multirow{2}{*}{$\begin{array}{l}\mathrm{CV} \\
(\%)\end{array}$} \\
\hline & 0 & 8 & 16 & 24 & \\
\hline 0 & $7,18 \mathbf{A b}$ & $7,40 \mathbf{~ D b}$ & $8,90 \mathbf{A b a}$ & 9,20 Всa & \\
\hline 3 & 6,93 Ac & 7,72 CDb & $9,48 \mathbf{A a}$ & 9,01 Bca & \\
\hline 7 & 7,07 $\mathbf{A b}$ & 7,73 CDb & 9,51 Aa & 9,57 Aba & \\
\hline 14 & 7,24 Ab & $7,40 \mathbf{D b}$ & 9,40 Aa & $8,77 \mathbf{C a}$ & 2,03 \\
\hline 21 & 6,98 Ac & 9,11 Ab & 9,49 Aab & 9,94 Aa & \\
\hline 28 & $7,23 \mathbf{A b}$ & $8,8 \mathbf{A b a}$ & $9,34 \mathbf{A a}$ & 9,03 Bca & \\
\hline 35 & 6,89 Ac & $8,22 \mathbf{B C b}$ & $8,45 \mathbf{~ B b}$ & 9,97 Aa & \\
\hline
\end{tabular}

Médias seguidas pela mesma letra maiúscula na mesma coluna e pela mesma letra minúscula na mesma linha não diferem pelo Teste de Tukey $(\mathrm{P}>0,05)$

Os teores de proteína bruta $(\mathrm{PB})$ das silagens foram elevados $(\mathrm{P}<0,05)$ com a substituição do BCD, onde o maior teor de PB (9,97\%) foi obtido nas silagens com $24 \%$ de BCD oriunda dos silos que foram abertos após 35 dias de armazenamento (Tabela 2). Nas silagens com 0\% de BCD foram encontrados os menores teores de PB (6,89\%). Verificou-se que os maiores teores de PB foram obtidos nos dois maiores níveis de substituição do BCD (16\% e 24\%). As exceções para esta afirmativa foram observadas apenas no $21^{\circ}$ e $28^{\circ}$ dias de armazenamento dos silos, quando as silagens contendo o BCD apresentaram valores semelhantes $(\mathrm{P}>0,05)$, com diferenças $(\mathrm{P}<0,05)$ apenas quando estes mesmos valores foram comparados aos obtidos nas silagens sem adição do $\operatorname{BCD}(6,98$ e $7,23 \%$, respectivamente).

O processo fermentativo da ensilagem, quando eficiente, tende a causar os menores danos possíveis aos componentes proteicos e energéticos do material ensilado, garantindo a manutenção da qualidade da silagem, em termos nutricionais semelhantes ao material pré-ensilado. Para que isto possa acontecer, a duração do processo de fermentação deve ser aquela necessária para que as maiores quantidades de ácidos orgânicos sejam produzidas para que os valores de pH possam ser 
reduzidos e promovam a paralisação da atividade microbiana indesejáveis dentro do silo, garantindo assim a obtenção da silagem como produto final.

Com base no exposto, é de se esperar que quanto mais tempo o processo fermentativo demore, haverá a tendência de diminuição dos constituintes nutricionais da planta, dentre eles a proteína, uma vez que os processos de proteólise podem ocorrer em maior ou menor extensão ao longo das diferentes fases do processo.

Ao se avaliar os diferentes tempos de armazenamento dos silos, e a consequente variação no que diz respeito aos teores de PB das silagens, verificou-se que sem a adição do BCD não foram encontradas diferenças para os componentes proteicos e que com adição de $16 \%$, estes teores só foram reduzidos nas silagens que passaram por 35 dias de processo fermentativo. No caso das silagens com 8 e 24\% de BCD, os teores de PB não acompanharam o mesmo tipo de resposta exposta acima, sendo, neste caso, verificado uma grande variação nos teores de proteínas ao longo dos dias de armazenamento.

Destaca-se que mesmo as silagens que não receberam o BCD no momento da ensilagem apresentaram teores de proteína bruta acima dos valores mínimos de 6 a 8\%, citados por Van Soest (1994) como necessários para a ocorrência de uma boa fermentação ruminal nos casos de consumo exclusivo desta fonte alimentar. As demais silagens produzidas com 8; 16 e 24\% de BCD naturalmente possuiriam teores proteicos superiores, já que o BCD possui 6,35 unidades percentuais a mais de PB do que o sorgo quando pré-ensilados, desde que o processo fermentativo ocorresse de forma eficiente com a menor ocorrência possível de processos proteolíticos.

A substituição da forragem de sorgo por 8 e $16 \%$ de BCD na ensilagem não promoveu diferenças $(\mathrm{P}>0,05)$ nos teores de FDN das silagens quando estes foram comparados aos teores obtidos nas silagens sem substituição da forragem de sorgo na maioria dos tempos de armazenamento (Tabela 3). Apenas a silagem proveniente da abertura de minissilos com 28 dias de armazenamento e $16 \%$ de $\mathrm{BCD}$ diferiram $(\mathrm{P}<0,05)$ dos mesmos teores encontrados nas silagens com 0 e $8 \%$.

As variações observadas nos teores de FDN dentro de cada nível de substituição pelo BCD, em relação aos diferentes dias de abertura dos silos, pouco contribuíram para que se pudesse concluir sobre os efeitos dos diferentes dias da ocorrência do processo fermentativo sobre os teores de FDN das silagens. Os maiores valores numéricos para esta variável foram obtidos nas silagens com $24 \%$ no $21^{\circ}$ de armazenamentos $(63,42 \%)$ enquanto que os menores foram observados nas silagens sem adição do BCD no momento da ensilagem $(47,44 \%)$. 
De acordo com Van Soest (1994) a proporção da parede celular que sofreu lignificação associada a quantidade do conteúdo celular podem determinar as características e o valor nutritivo dos alimentos e forragens. A FDN corresponde à reconstituição da parede celular com os seus principais componentes (celulose, hemiceluloses e lignina) e esta pode determinar o maior ou menor consumo dos alimentos dependendo da sua concentração presente.

Tabela 3 - Teores médios de fibra em detergente neutro (FDN) de silagens de sorgo (Sorghum bicolor, L.) associada a níveis crescentes do bagaço de caju (Anacardium occidentale,L.) desidratado em diferentes tempos de armazenamento

\begin{tabular}{|c|c|c|c|c|c|}
\hline \multirow{2}{*}{$\begin{array}{c}\text { Dias de } \\
\text { armazenamento }\end{array}$} & \multicolumn{4}{|c|}{ Níveis de substituição do bagaço do caju desidratado (\%) } & \multirow{2}{*}{$\begin{array}{l}\mathrm{CV} \\
(\%)\end{array}$} \\
\hline & 0 & 8 & 16 & 24 & \\
\hline 0 & $47,44 \mathbf{C b}$ & $52,91 \mathbf{B b}$ & $54,29 \mathbf{B b}$ & $58,21 \mathbf{B a}$ & \\
\hline 3 & $56,90 \mathbf{A a}$ & $55,17 \mathbf{B a}$ & 57,62 Aba & $57,62 \mathbf{B a}$ & \\
\hline 7 & $55,36 \mathbf{A B a}$ & $56,20 \mathbf{B a}$ & $56,53 \mathbf{B a}$ & $57,58 \mathbf{B a}$ & \\
\hline 14 & $56,64 \mathbf{A b}$ & 60,53 Aab & 57,04 ABab & $61,05 \mathbf{A b a}$ & 1,67 \\
\hline 21 & 56,53 ABbc & $53,37 \mathbf{B c}$ & $57,70 \mathbf{A B b}$ & 63,42 Aa & \\
\hline 28 & $52,72 \mathbf{B b}$ & $54,05 \mathbf{B b}$ & 60,89 Aa & 61,09 Aba & \\
\hline 35 & 58,51 Aab & 55,97 Bb & 58,34 ABab & 60,71 Aba & \\
\hline
\end{tabular}

Médias seguidas pela mesma letra maiúscula na mesma coluna e pela mesma letra minúscula na mesma linha não diferem pelo Teste de Tukey $(\mathrm{P}>0,05)$

A adição do BCD proporcionou elevações nos teores de FDN das silagens, principalmente quando se adicionou 16 e $24 \%$ de $\mathrm{BCD}$, e isto pode promover a redução do consumo voluntário dos animais alimentados com estas silagens devido ao consumo de maiores teores de fibra (Mertens 1992). Este autor explica que ao se consumir alimento com elevado teor de fibra e baixa concentração de energia (característico de alimentos volumosos) o consumo voluntário é limitado pelo efeito do enchimento físico do alimento exercido no rúmen. Para Candido et al. (2007), níveis iguais ou acima de $70 \%$ provocam limitação quanto ao consumo.

A substituição da forragem de sorgo pelo BCD elevou $(\mathrm{P}<0,05)$ os teores de FDA das silagens, principalmente quando foram comparadas as silagens associadas ao BCD e a silagem de sorgo (Tabela 4). Quando se comparou as silagens com os diferentes níveis de substituição pelo $\mathrm{BCD}$ grande parte das diferenças não foram significativas $(\mathrm{P}>0,05)$.

Os materiais da pré-ensilagem, sem associação com o BCD, apresentaram os menores teores de FDA $(25,63 \%)$, enquanto que o nível de $16 \%$ de substituição e aos três dias de armazenamento dos silos foram verificados os maiores teores de FDA $(39,01 \%)$. 
Elevações nos teores de FDA podem promover a diminuição da digestibilidade dos alimentos, pois se elevam as concentrações dos teores lignocelulósicos que possuem muito baixa possibilidade de aproveitamento durante o processo de digestão ruminal (Mertens, 1992). Os níveis de $\mathrm{BCD}$ por possuírem maiores componentes lignocelulósicos $(46,17 \%)$ do que a forragem de sorgo $(32,42 \%)$ no momento da ensilagem, contribuíram para as elevações nos teores de FDA das silagens produzidas.

Tabela 4 - Teores médios de fibra em detergente ácido (FDA) de silagens de sorgo (Sorghum bicolor, L.) associada a níveis crescentes do bagaço de caju (Anacardium occidentale,L.) desidratado em diferentes tempos de armazenamento

\begin{tabular}{clllll}
\hline \multirow{2}{*}{$\begin{array}{c}\text { Dias de } \\
\text { Armazenamento }\end{array}$} & \multicolumn{2}{c}{ Níveis de substituição do bagaço do caju desidratado (\%) } & CV \\
\cline { 2 - 4 } & \multicolumn{1}{c}{0} & \multicolumn{1}{c}{8} & \multicolumn{1}{c}{16} & \multicolumn{1}{c}{24} & $(\%)$ \\
\hline 0 & $25,63 \mathbf{C c}$ & $31,34 \mathbf{A B b}$ & $35,17 \mathbf{A B a}$ & $33,51 \mathbf{~ B C a b}$ & \\
3 & $30,29 \mathbf{A b}$ & $32,01 \mathbf{A B b}$ & $39,01 \mathbf{A a}$ & $32,91 \mathbf{~ C b}$ & \\
7 & $28,45 \mathbf{A B C c}$ & $32,00 \mathbf{A B b}$ & $35,10 \mathbf{B a b}$ & $37,81 \mathbf{A a}$ & \\
14 & $27,38 \mathbf{A B C b}$ & $33,42 \mathbf{A a}$ & $36,25 \mathbf{A B a}$ & $36,36 \mathbf{A b a}$ & 2,56 \\
21 & $29,52 \mathbf{A b c}$ & $29,82 \mathbf{~ B c}$ & $34,31 \mathbf{~ B b}$ & $38,43 \mathbf{A a}$ & \\
28 & $26,73 \mathbf{~ B C c}$ & $32,89 \mathbf{A B a b}$ & $29,94 \mathbf{C b c}$ & $36,10 \mathbf{A B C a}$ & \\
35 & $30,51 \mathbf{A b c}$ & $29,54 \mathbf{~ B c}$ & $38,75 \mathbf{A a}$ & $33,07 \mathbf{~ B C b}$ & \\
\hline
\end{tabular}

Médias seguidas pela mesma letra maiúscula na mesma coluna e pela mesma letra minúscula na mesma linha não diferem pelo Teste de Tukey $(\mathrm{P}>0,05)$

\section{Conclusões}

A substituição da forragem de sorgo pelo bagaço de caju desidratado no momento da ensilagem pode ser realizada em até $16 \%$ por não comprometeu composição química da silagem.

\section{Referências}

ALMEIDA, Jean Sardinha de et al. Utilização de subprodutos de frutas na alimentação animal. Revista Eletrônica Nutrime, Goiás, v. 11, n. 03, p.3430-3443, maio/junho 2014.

ALMEIDA, S.C., DÖRR, A.C., ZULIAN, A., e SIDALI, K.L. Análise econômica da citricultura de Rosário do Sul/RS: um enfoque sobre a adoção de programas de certificação socioambiental. Revista. Eletrônica em Gestão, Educação e Tecnologia Ambiental, Santa Maria, v. 11, n. 11, p.2427-2436, jun. 2013. 
CANDIDO, Magno José Duarte et al. Características fermentativas e composição química de silagens de capim-elefante contendo subproduto desidratado do maracujá. Revista Brasileira de Zootecnia, Viçosa, v. 36, n. 5, p.1489-1494, 14 maio 2007.

DANTAS FILHO, L.A. et al. Inclusão de polpa de caju desidratada na alimentação de ovinos: desempenho, digestibilidade e balanço de nitrogênio. Revista Brasileira de Zootecnia, v.36, n.1, p.147-154, 2007.

DETMANN, E. et al. Métodos para análise de alimentos. Visconde do Rio Branco, MG: Suprema, 2012. 214p.

FERREIRA, A.C.H., NEIVA, J.N.M., RODRIGUEZ, N.M., LOBO, R.N.B. e VASCONCELOS, V.R. Valor nutritivo das silagens de capim-elefante com diferentes níveis de subprodutos da indústria do suco de caju. Revista Brasileira de Zootecnia, v.33, n.6, p.1380-1385, 2004.

formulation. In: SIMPÓSIO INTERNACIONAL DE RUMINANTES, 1992, Lavras. Anais..., Lavras: SBZ, 1992. p,1-33.

HOLANDA, J. S.; TORRES, J. F; OLIVEIRA, M. T; FERREIRA FILHO, L.; HOLANDA, A. C. Da carne de caju à carne de cordeiro. Natal: Emparn, 2010. 42 p.

IBGE - Instituto Brasileiro de Geografia e Estatística. Produção da Pecuária Municipal. Rio de Janeiro, 2016. Disponível em:

<http://www.ibge.gov.br/home/estatistica/economia/ppm/tabelalppm.shtm>. Acessado em: 28 jan. 2017.

LEITE, D.F.L., AGUIAR, E.M., HOLANDA, J.S., RANGEL, A.H.N, AURELIANO, I.P.L,

MEDEIROS, V.B. e LIMA JÚNIOR, D.M. Valor nutritivo do resíduo de caju desidratado associado a diferentes concentrados. Acta Veterinaria Brasilica, v.7, n.1, p.66-72, 2013.

MERTENS, D.R. Analysis of fiber in feeds and its use in feed evaluation and ration formulation. In: SIMPÓSIO INTERNACIONAL DE RUMINANTES, 1992, Lavras. Anais..., Lavras: SBZ, 1992. p,1-33.

MORAES, S. A. de. Subprodutos da agroindústria e indicadores externos de digestibilidade aparente em caprinos. 2007, 57f. Tese (Doutorado) - Escola de Veterinária, Universidade Federal de Minas Gerais, Belo Horizonte.

NEUMANN, M.; RESTLE, J.; ALVES FILHO, D.C.; BRONDANI, I.L.; PELLEGRINI, L.G.; FREITAS, A.K. Avaliação do valor nutritivo da planta e da silagem de diferentes híbridos de sorgo (Sorghum bicolor, L. Moench). Revista Brasileira de Zootecnia, Viçosa, v. 31, n. 1, supl. p. 293301, jan. 2002.

OLIVEIRA, Leandro Barbosa de et al. Produtividade, composição química e características agronômicas de diferentes forrageiras. Revista Brasileira de Zootecnia, v. 11, n. 38, p.2111-2115, 2010. Disponível em: <http://www.scielo.br/pdf/rbz/v39n12/a07v39n12.pdf>. Acesso em: 21 abr. 2017.

RAMOS, L. S. N; LOPES, J. B.; FIGUEIREDO, A. V.; FREITAS, A. C.; FARIAS, L. A.; SANTOS, L.S.; SILVA, H. O. Polpa de caju em rações para frangos de corte na fase final: desempenho e característica da carcaça. Revista Brasileira de Zootecnia, v. 35, n. 3, p. 804-810, 2006. 
RODRIGUES, Roberto. FRUTAS PARA O MUNDO. 2015. Disponível em: <http://gvagro.fgv.br/sites/gvagro.fgv.br/files/u5/01 2015 - FRUTAS PARA O MUNDO.pdf>. Acesso em: 15 maio 2017.

ROSA, Wilson José. Cultura do Sorgo. 2012. Série Ciências Agrárias. Disponível em: <http://www.emater.mg.gov.br/doc/intranet/upload/MATERIAL_TECNICO/a cultura do sorgo.pdf >. Acesso em: 27 jan. 2017.

SILVEIRA, A. C. Técnicas para produção de silagens In: Simpósio sobre Manejo de Pastagens, $2^{\circ}$ Piracicaba, ESALQ, 1975. Anais. P. 156-180.

SIQUEIRA, A. M. de A.; BRITO, E. de S. Aproveitamento do bagaço do caju para alimentação humana e utilização em outras indústrias de alimentos. In: ARAÚJO, J. P. P. de. (Ed.). Agronegócio caju: práticas e inovações. Brasília, DF: Embrapa, 2013. Parte 5, cap. 3, p. 349-362 VAN SOEST, P.J. 1994. Nutritional ecology of the ruminant. 2 ed. Ithaca: Cornell University Press. 476p. 